\title{
DESIGN \& SIMULATION OF DUAL BAND T-SHAPED SLOT MICRO STRIP ANTENNA FOR C-BAND APPLICATIONS
}

\author{
M. Ravi Kishore ${ }^{1}$, A.Janardhana ${ }^{2}$, B.Murali Krishna ${ }^{3}$ \\ ${ }^{1}$ Associate Professor, Department of ECE, Sri Sivani College of Engineering, Srikakulam, Andhra Pradesh, INDIA. \\ mrkishore7709@gmail.com \\ ${ }^{2}$ Assistant Professor, Department of ECE, Sri Sivani College of Engineering, Srikakulam, Andhra Pradesh, INDIA. \\ janardhana.arsavelli@gmail.com \\ ${ }^{3}$ Assistant Professor Department of ECE, Sri Sivani Institute of Technology, Srikakulam, Andhra Pradesh, INDIA. \\ muralikrishna.bonthu@gmail.com
}

\begin{abstract}
Microstrip patches radiate from the currents induced on the surface of the patch because of the electromagnetic cavity with significant resonant frequencies formed between patch and ground plane according to the frequencies applied with different feeding techniques. This paper presents the design and simulation of a T-shaped Dual band Microstrip patch antenna with operating frequencies $5.40 \mathrm{GHz}$, and $6.60 \mathrm{GHz}$ for $\mathrm{C}$-Band applications. The T-shape provides Dual band characteristics with good bandwidth which is required in wireless devices with significant design characteristics and can be easily mounted on air craft, space craft, satellites, missiles etc., An Edge-Fed microstrip with substrate FR4epoxy having dielectric constant 4.4 and substrate heights of $6.5 \mathrm{~mm}, 4.56 \mathrm{~mm}, 3.048 \mathrm{~mm}$, and $1.524 \mathrm{~mm}$ are designed and analyzed with different parameters like VSWR, Gain, Peak directivity, Return losses, Bandwidth, Radiation efficiency, FBR etc.. This antenna design is an improvement from previous research and it is simulated using HFSS (High Frequency Structure Simulator) version 13.0 software.
\end{abstract}

Keywords :T-shaped slot microstrip,Dual Band, C-Band, Edge-Fed, HFSS Software 13.0 $* * *$

\section{INTRODUCTION}

Microstrip patch antenna consists of a metallic patch with different configurations and shapes on a grounded substrate. These antennas are more popular because of their design, ease of analysis and fabrication. The feasible Design and Radiation characteristics highlight its significance in the wireless communication industry. The design characteristics include low profile, simple and inexpensive to fabricate using different methods of printed circuit technologies especially compatible to MMIC designs and comfortable to planer, non planer and rigid surfaces with robust structures [5]. The radiation characteristics include good resonant frequencies, Efficiency, Gain, Polarization, Radiation Pattern and Impedance.

The C-Band is a widely used microwave frequency band in wireless communication systems including Radars, Satellites, Aircrafts, Spacecrafts, missiles and in several space borne applications. The IEEE C-Band (4 to $8 \mathrm{GHz}$ ) and its sub band frequencies are feasible also for modern wireless communication systems include Wi-Fi, WLAN, Wi-MAX, Bluetooth etc,[10]. The C-Band performs better under adverse weather conditions compared to other microwave bands used in other applications.

In this paper, a Dual band microstrip patch antenna has been designed, simulated, and analyzed the performance using Finite Element Method based tool, HFSS (High Frequency Structure Simulator) software version 13.0. A T-shaped microstrip patch antenna with substrate of FR4epoxy material and fed with Edge-feed system is developed on Ansys HFSS platform and analyzed to observe the different antenna performance parameters at different frequencies of operations. This paper is structured as follows. Section II describes methodology followed for design of microstrip patch, design parameters and geometry. Section III shows the results explaining antenna parameters like Radiation pattern, Return loss, VSWR, Gain with specifications tabulated and finally Section IV is conclusion.

\section{METHODOLOGY}

\subsection{Design of T-shaped Microstrip Slot}

In this section there is presented a design with the use of Microwave HFSS simulation software. First of all we have to choose a dielectric constant and substrate height to design an antenna as these are the basics for the designing[9][8]. They were chosen according to the design frequency. There was chosen substrate material is FR4epoxy with dielectric constant 4.4.

The width of the patch is $0.3 \mathrm{~mm}$ which is copper (annealed) material having the relative permeability, electrical conductivity $(\sigma)$ and relative density $(\rho)$ of $1.0,5.8 \times 10^{\wedge} 7$ $(\mathrm{S} / \mathrm{m})$ and $8900(\mathrm{~kg} / \mathrm{m} 2)$ respectively[1]. The antenna is fed with $50 \Omega$ microstrip transmission line. Figure 1 shows the geometry of the proposed antenna. The lengths and widths of patch is represented in Table1. 


\subsection{Designing parameters:}

* Calculation of the Width ( W)

* Calculation of Effective dielectric constant $\left(\varepsilon_{\text {reff }}\right)$

* Calculation of the Effective length $\left(L_{\text {reff }}\right)$

* Calculation of the length extension $(\Delta \mathrm{L})$

* Calculation of actual length of patch (L).

\subsection{Designing Equations}

The below equations are used to find out the length and width of patch [3][4]. The width of the patch is found by

$$
W=\frac{1}{2 f_{r} \sqrt{\mu_{0} \varepsilon_{0}}} \sqrt{\frac{2}{\varepsilon_{r}+1}}=\frac{v_{0}}{2 f_{r}} \sqrt{\frac{2}{\varepsilon_{r}+1}}
$$

Where the $v_{0}$ is the free-space of velocity of light The effective dielectric constant can then found by

$\varepsilon_{e f f}=\frac{\varepsilon_{r}+1}{2}+\frac{\varepsilon_{r}-1}{2}\left[1+12 \frac{t}{W}\right]-0.5$

The extension length has been adapted into the form

$\Delta \mathrm{L}=0.412 \mathrm{t} \frac{\left(\varepsilon_{e f f}+0.3\right)\left(\frac{W}{t}+0.264\right)}{\left(\varepsilon_{e f f}-0.258\right)\left(\frac{W}{t}+0.8\right)}$

The actual length of patch( $\mathrm{L}$ ) can be determined as

$L=\frac{1}{2 f_{r} \sqrt{\varepsilon_{r e f f}} \sqrt{\mu_{0} \varepsilon_{0}}}-2 \Delta L$

\subsection{Geometry of Antenna}

The geometry of the designed antenna is shown in the Figure 1.The antenna is made of a single patch on top, one layers of dielectric and a edge feed slot connected to the upper patch. The shape of the patch $\mathrm{T}$ enables with two small arms radiate a particular range of resonance frequencies, the copper material adds the radiation efficiency in the required direction with good front-to-back ratio [1]. The construction and structure with the combination of epoxy substrate enables the antenna to radiate with low VSWR to avoid the reflections. All the dimensions are optimum for effective radiation pattern with good directivity in the given operating frequencies. The specification of dimensions of the patch is represented with widths(w) and heights(h).

\begin{tabular}{|l|l|l|l|l|l|l|l|}
\hline Dimension & W1 & W2 & W3 & h1 & h2 & h3 & h4 \\
\hline Specification(mm) & 28 & 4 & 20 & 45 & 8 & 17 & 1.5 \\
\hline
\end{tabular}

Table.1: Antenna specifications

The design of the proposed antenna is done with the tools available in the HFSS 13.0 software platform and represented in Figure 2. The edge feeding technique is used to assign the excitation to the patch directly at the edges of the patch and substrate.

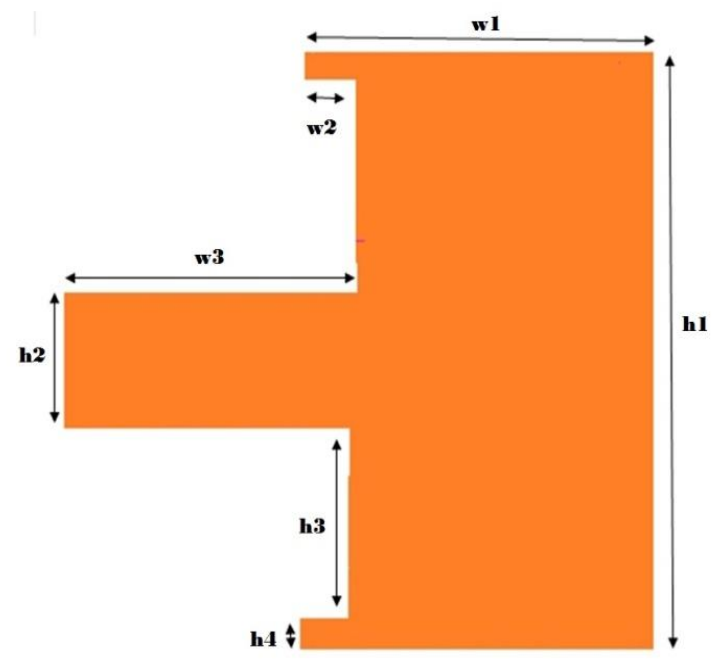

Figure1: Design geometry of proposed micro strip patch.

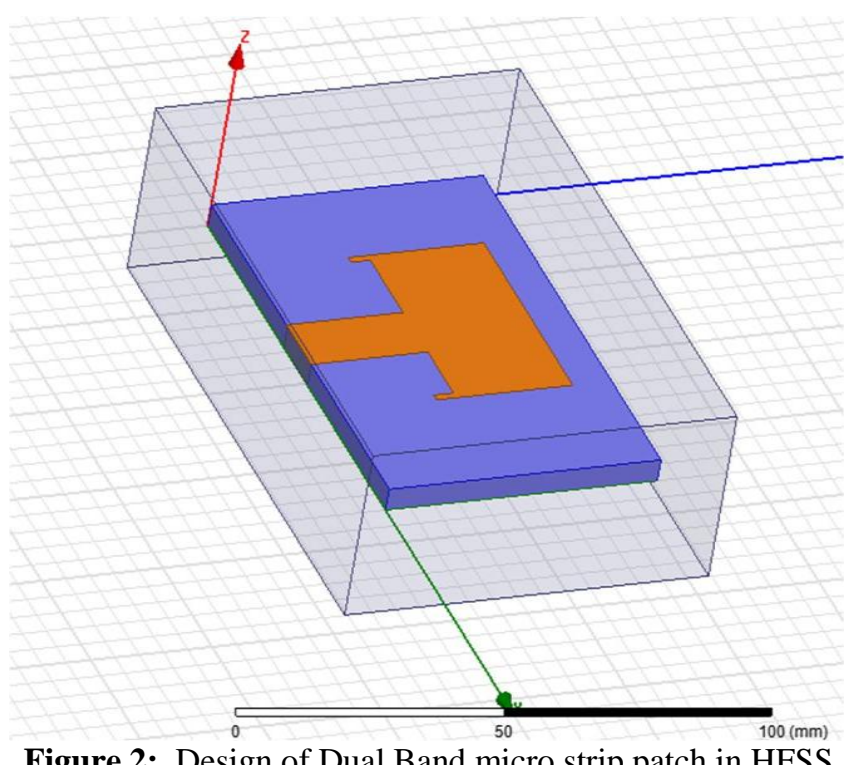

Figure 2: Design of Dual Band micro strip patch in HFSS software

\section{RESULTS AND EXPLANATIONS}

\subsection{Return Losses}

Figure 3 illustrates both the simulated and experimental results of the antenna return loss. Here, Return loss is defined as

$$
R=20 \log 10|K|
$$

where $\mathrm{K}$ is the reflection coefficient. The Return loss is related with the VSWR and operating frequencies. As shown in this figure 3 , simulated values of the first and second resonant frequencies are $5.4 \mathrm{GHz}$ and $6.6 \mathrm{GHz}$, respectively. Current paths of the 1st and2nd modes are shown. The resonant frequencies can be calculated approximately as follows:

$$
f_{1}=\frac{c}{2 \sqrt{\varepsilon_{e f f}} L 1}
$$


$f_{2}=\frac{c}{2 \sqrt{\varepsilon_{e f f}} L 2}$

Where $L 1$ and $L 2$ are the average lengths for current paths of the $1^{\text {st }}$ and 2 nd resonant modes and $c$ is the velocity of EM wave in free space. The effective dielectric constant is given by

$\varepsilon_{e f f}=\frac{\varepsilon_{r}+1}{2}+\frac{\varepsilon_{r}-1}{2}\left(1+\frac{10 t}{W}\right)^{-0.555}$

Where $t$ and $W$ are thickness of the substrate and width of the metallic patch. The return losses are shown in the below Figure 3.

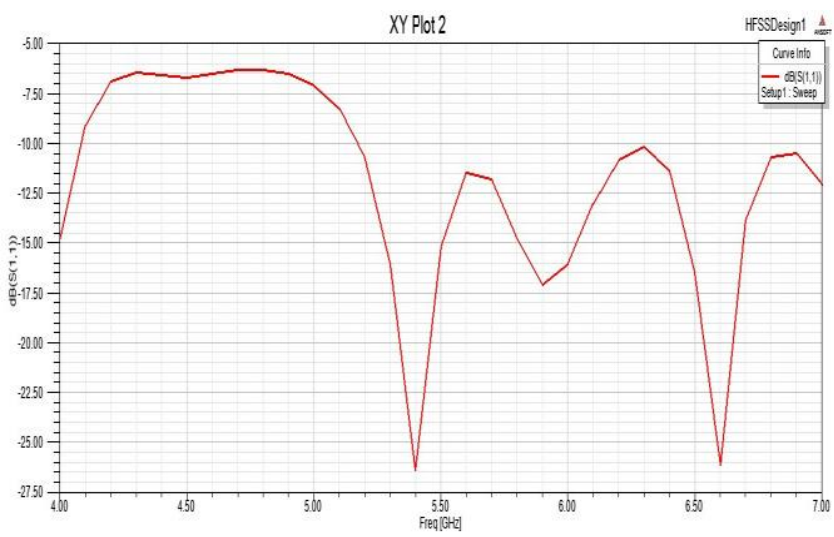

Figure 3: Return losses

\subsection{Radiation Pattern}

The two dimensional radiation pattern can be plotted by taking the variation of the absolute value of field strength or power as a function of $\theta$. This curve gives the necessary Directional characteristics of the antenna include HPBW, FNBW, Direction of Propagation, FBR etc., Significant changes in the values of thickness of the substrate, dielectric constant of the substrate, shape of the patch, effective length, Feed position, W/L Ratio effect the Directional characteristics of the Proposed microstip antenna. The radiation pattern visualizes the propagation characteristics of the antenna for optimization.

The radiation Pattern of the proposed antenna is shown in below figures 4

\section{E}
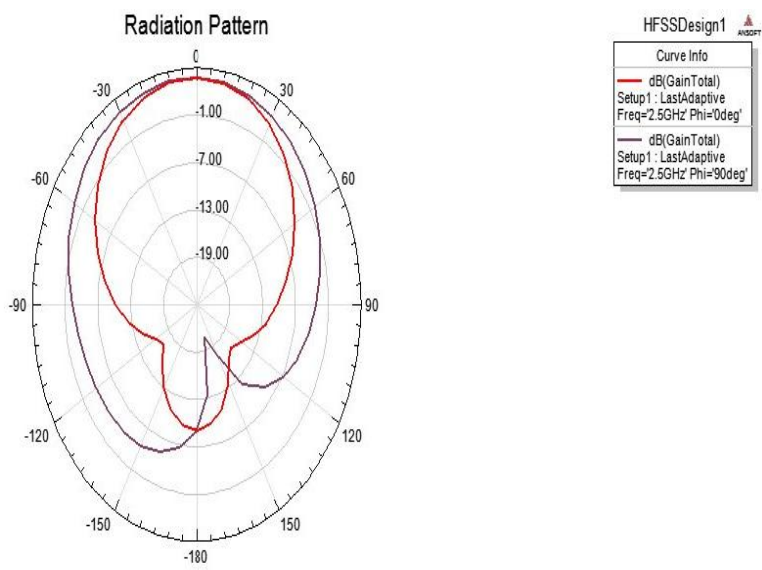

Figure 4: Radiation pattern

\subsection{3-D Radiation Pattern}

The radiation pattern is the variation of the power radiated or electric field intensity or absolute Gain as a function of three dimensional space coordinates[5][6]. It is main concentration for the wide band applications.

The Figure 4 and 5 show the radiation pattern for the antenna at $5.4 \mathrm{GHz}$. HPBW is the angular separation between half power points of the radiation. HPBW (angle) is observed $60^{\circ}$ for Optimum Frequency of $5.4 \mathrm{GHz}$.
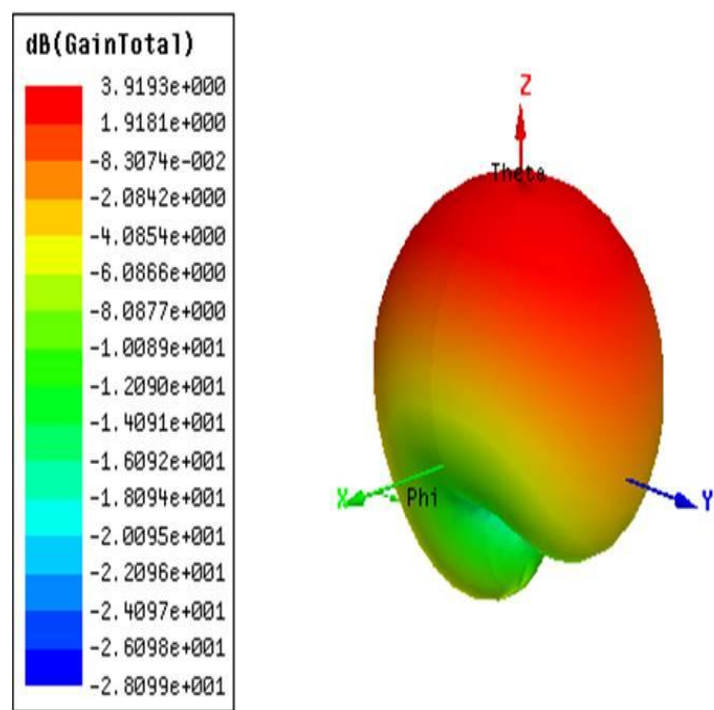

Figure5: 3D-view of radiation pattern

\subsection{Field Distribution}

The E-field distribution and H-Field distribution for this design is

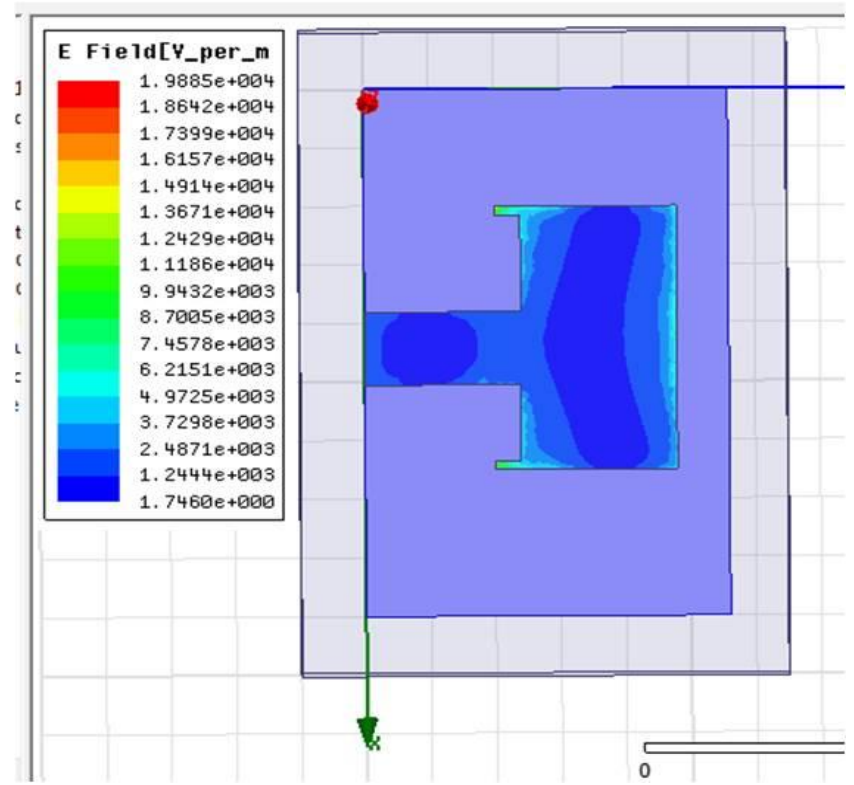

Figure 6: E-field distribution for T-shape micro strip patch antenna

Significant variations in the $\mathrm{E}$ and $\mathrm{H}$ fields can be observed in the figure 6 and 7 respectively. 


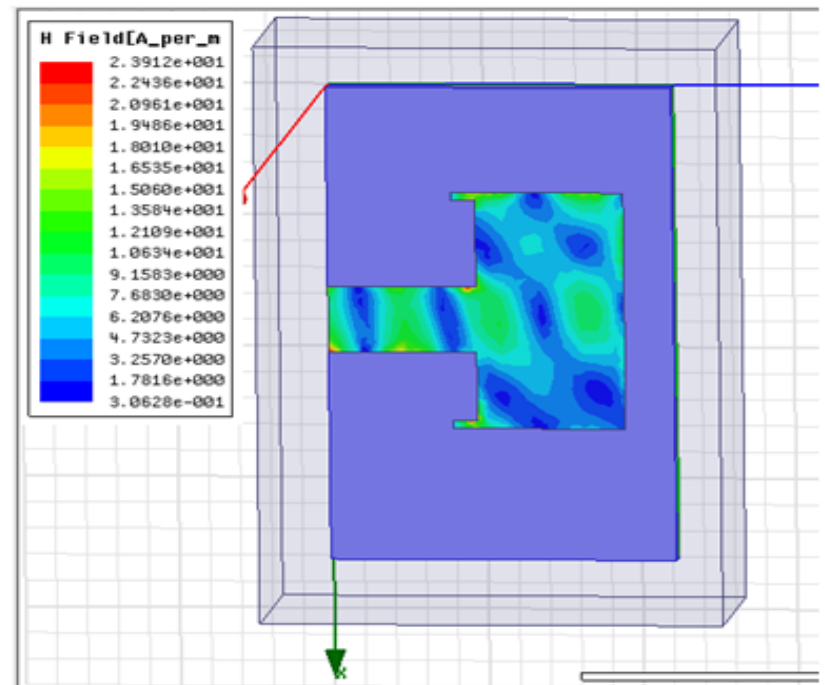

Figure 7: H-field distribution for T-shape micro strip patch antenna

\subsection{VSWR}

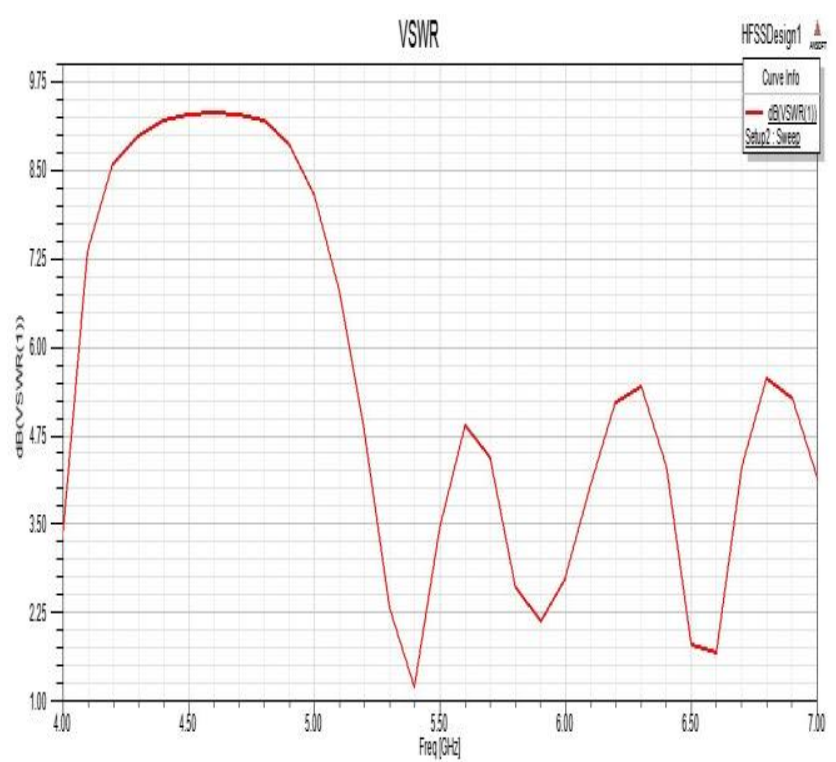

Figure 8: VSWR for E-shape patch antenna

\subsection{Gain}

Another useful measure describing the performance of an antenna is the Gain. It is the measure of the effectiveness of the antenna radiation in the desired direction with less antenna losses. Its value can be obtained by taking the intensity of radiation with reference to the total input power to the antenna for entire solid angle covering radiation. The similar parameter directivity is a theoretical measure that describes only the directional properties of the antenna without considering the losses [5][6]. And therefore Gain of an antenna (in a given direction) is defined as "The ratio of $4 \pi$ times radiation intensity to the total input power". Radiation from the Isotropic radiator is the reference to define Gain. And it is given by

Gain $=4 \pi \frac{\text { radiation intensity }}{\text { total input power }}=4 \pi \frac{U(\theta, \varphi)}{p_{\text {in }}}$

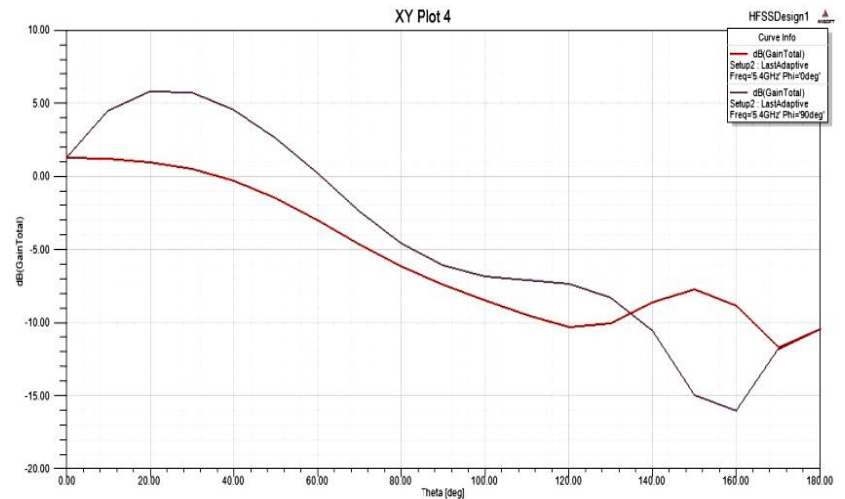

Figure 9: Two dimensional variation of gain

\subsection{Antenna Radiation Parameters At Different}

\section{Frequencies And Thickness}

\begin{tabular}{|l|l|l|l|}
\hline Frequency(GHz) & $\mathbf{2 . 5}$ & $\mathbf{5 . 4}$ & $\mathbf{6 . 6}$ \\
\hline Gain (dB) & 2.46562 & 3.89944 & 3.22377 \\
\hline $\begin{array}{l}\text { Radiation Efficiency } \\
(\%)\end{array}$ & 64.7632 & 64.6174 & 58.1091 \\
\hline Max U(W/Sr) & 0.127889 & 0.308818 & 0.255279 \\
\hline Peak Directivity & 3.80713 & 6.03466 & 5.54779 \\
\hline Radiated Power(W) & 0.422141 & 0.643086 & 0.57825 \\
\hline Accepted Power(W) & 0.651822 & 0.995221 & 0.995112 \\
\hline Incident Power(W) & 1 & 1 & 1 \\
\hline
\end{tabular}

Table 2: Values for radiation parameters for each frequency at substrate thickness $\mathbf{t}=\mathbf{4 . 5 6} \mathbf{m m F}$ or $\mathbf{t}=\mathbf{6 . 5 m m}$

\begin{tabular}{|l|l|l|}
\hline Frequency(GHz) & $\mathbf{5 . 4}$ & $\mathbf{6 . 6}$ \\
\hline Gain (dB) & 2.72829 & 3.83917 \\
\hline Radiation Efficiency (\%) & 71.0014 & 66.689 \\
\hline Max U(W/Sr) & & \\
\hline Peak Directivity & 0.203426 & 0.284859 \\
\hline Radiated Power(W) & 3.84258 & 5.75682 \\
\hline Accepted Power(W) & 0.66528 & 0.621822 \\
\hline Front-to-Back Ratio & 0.936996 & 0.932422 \\
\hline Incident Power(W) & 84.1909 & 7.51838 \\
\hline Table 3: Radiation parameters & 1 & 1 \\
\hline
\end{tabular}

Table 3: Radiation parameters for each frequency at substrate thickness $\mathbf{t}=\mathbf{6 . 5} \mathbf{m m}$ for $\mathbf{t}=\mathbf{3 . 0 4 8 m m}$ 


\begin{tabular}{|l|l|l|}
\hline Frequency(GHz) & $\mathbf{5 . 4}$ & $\mathbf{6 . 6}$ \\
\hline Gain (dB) & 4.75636 & 1.73123 \\
\hline Radiation Efficiency (\%) & 56.1713 & 46.4233 \\
\hline Max U(W/Sr) & 0.362876 & 0.124697 \\
\hline Peak Directivity & 8.46759 & 3.72921 \\
\hline Radiated Power(W) & 0.538541 & 0.420204 \\
\hline Accepted Power(W) & 0.958747 & 0.905157 \\
\hline Front-to-Back Ratio & 30.5743 & 19.9883 \\
\hline Incident Power(W) & 1 & 1 \\
\hline
\end{tabular}

Table 4: Radiation parameters for each frequency at substrate thickness $\mathbf{t}=\mathbf{3 . 0 4 8} \mathbf{m m}$ for $\mathbf{t}=\mathbf{1 . 5 2 4} \mathbf{m m}$

\begin{tabular}{|l|l|l|}
\hline Frequency(GHz) & $\mathbf{5 . 4}$ & $\mathbf{6 . 6}$ \\
\hline Gain $(\mathrm{dB})$ & 3.23041 & 1.22299 \\
\hline Radiation Efficiency $(\%)$ & 37.3072 & 28.8526 \\
\hline Max U(W/Sr) & 0.116243 & 0.0552133 \\
\hline Peak Directivity & 8.65894 & 4.23874 \\
\hline Radiated Power(W) & 0.168703 & 0.163692 \\
\hline Accepted Power(W) & 0.452198 & 0.567337 \\
\hline Front-to-Back Ratio & 21.4827 & 44.6343 \\
\hline Incident Power(W) & 1 & 1 \\
\hline
\end{tabular}

Table 5: Radiation parameters for each frequency at substrate thickness $\mathbf{t}=\mathbf{1 . 5 2 4} \mathbf{m m}$

It is observed that the proposed antenna has the return losses of -26.50 and -26.00 with the VSWR of 1.20 and 1.60 at $5.4 \mathrm{GHz}$ and $6.6 \mathrm{GHz}$ respectively. From the simulation results of Table 3 , it is observed that at $t=6.5 \mathrm{~mm}$ the Radiation efficiency is significantly good, but with less Directivity and Gain. And a significant difference in the ranges of FBR is observed for the two interested frequencies.

From the simulation results of Table $4 \& 5$, it is observed that at $\mathrm{t}=3.048 \mathrm{~mm}$ and $1.524 \mathrm{~mm}$ the Directivity and gain are good but with poor Radiation Efficiency and FBR. The optimum results are observed at the substrate thickness of $\mathrm{t}=4.56 \mathrm{~mm}$ for the interested band of frequencies.

\section{CONCLUSION}

In this paper, a T-shaped Dual band microstrip patch antenna using FR4epoxy substrate excited with edge feed, and analyzed the performance using Finite Element Method based tool, HFSS (High Frequency Structure Simulator) software version 13.0. The performance of the designed antenna was analyzed in term of bandwidth, gain, return loss, VSWR, and radiation pattern. The design was optimized to meet the best possible result. Substrate used was FR4epoxy which has a dielectric constant of 4.4 with different substrate thicknesses. The results show the multiband antenna is able to operate with $5.4 \mathrm{GHz}$ and $6.6 \mathrm{GHz}$ frequencies for substrate thickness $4.56 \mathrm{~mm}$. Due to the frequency of operation and compact area occupied, the proposed antenna is well suited for different devices used in WLAN, Wi-Fi, WiMAX and in different wireless and C-band applications.

\section{REFERENCES}

[1]. Md. Ashikur Rahman, Moinul Hossain, Ibnul Sanjid Iqbal "Design and Performance Analysis of A Dualband Microstrip Patch Antenna for Mobile WiMAX, WLAN, Wi-Fi and Bluetooth Applications", 3rd International Conference on Informatics, Electronics \& Vision 2014

[2]. M. F. Ain, S. I. S. Hassan, J. S. Mandeep, M. A. Othman, and B. M.Nawang, "2.5 GHz BaTiO3 Dielectric Resonator Antenna", Progress In Electromagnetics Research, PIER 76, 201-210, 2007

[3]. M.R.Kishore, A.Janardhana "Design \& Performance Analysis of Double U-Slot Microstrip Antenna for WiMAX Application" International Journal of Advanced Research in Electronics and Communication Engineering (IJARECE) Volume 3, Issue 8, August 2014

[4]. M.R.Kishore, V.Jeevan Kumar "Design \& Simulation of E-shaped Micro Strip Patch Antenna for GPS Application" Int. Journal of Engineering Research and Applications ISSN : 2248-9622, Vol. 4, Issue 8( Version 5), August 2014, pp.94-100

[5]. C.A. Balanis, Antenna Theory, 2nd Ed. New York: John Wiley \& sons, Inc., 1997.

[6]. W.L. Stutzman and G.A. Thiele, Antenna Theory and Design, 2nd ed. New York: Wiley, 1998.

[7]. Hattan F. Abu Tarboush, D. Budimir, R. Nilavalan "Connected U-slots Patch Antenna for WiMAX Applications". International Journal of RF \& Microwave CAF, 2008.

[8]. D. M. Pozar, "Microstrip antennas," Proc. IEEE, vol. 80, no. 1, pp. 79-91, Jan. 1992.

[9]. Ramesh Garg, Parkash Bhartia, Inderbahl, Apisak Ittipiboon, Microstrip Antenna Design Handbook, A .V. Title. VI series.

[10]. "Design of C-Band Microstrip Patch Antenna for Radar Applications Using IE3D" IOSR Journal of Electronics and Communication Engineering (IOSRJECE) e-ISSN: 2278-2834,p- ISSN: 2278-8735. Volume 5, Issue 3 (Mar. - Apr. 2013), PP 49-58 